\title{
EDUCAÇÃO INCLUSIVA NA PERSPECTIVA \\ DOS PROFESSORES DE EDUCAÇÃO FISICA \\ DO MUNICÍPIO DE SANTO ANDRÉ
}

\begin{tabular}{c}
\hline INCLUSIVE EDUCATION \\
IN THE VIEW OF PHYSICAL EDUCATION \\
TEACHERS OF SANTO ANDRÉ CITY \\
\hline EDUCACIÓN INCLUSIVA EN LA PERSPECTIVA \\
DE LA EDUCACIÓN FÍSICA \\
MAESTRO DE SANTO ANDRÉ MUNICIPIO
\end{tabular}

Jorge Marcos Ramos ${ }^{1}$,
Ciro Winckler ${ }^{2}$,
Servio Antonio Bucioli $^{1}$

\section{RESUMO}

A educação no Brasil só foi introduzida como um assunto importante de acordo com a necessidade do momento e com a educação inclusiva não foi diferente, seu desenvolvimento começou a ser questionado a partir de movimentos insatisfeitos com a situação. O objetivo desta pesquisa foi verificar as atitudes dos professores de educação física em relação à presença de alunos com deficiências em suas aulas regulares, para tanto foi aplicado um questionário contendo 18 questões. Para verificar se existiam diferenças entre as proporções obtidas para cada afirmação, foi utilizado o teste Qui-Quadrado e o nível de significância adotado foi p<0,05. As diferenças foram significativas em 15 questões. Participaram da pesquisa 77 professores da rede regular de ensino do Município de Santo André. Dentre os participantes observou-se que a maioria deles acredita nas potencialidades desses alunos e que a inclusão é benéfica para todos àqueles que fazem parte da rotina escolar. Mesmo com essa consciência somente 2,6\% relataram que tinham conhecimento para trabalharem com os alunos com deficiência e 3,9\% se sentem preparados para trabalharem com esse grupo, contudo $74 \%$ dos professores relataram que pretendem participar de cursos e palestras relacionadas à pessoa com deficiência.

PALAVRAS-CHAVE: Educação inclusiva. Pessoas com deficiências. Educação física inclusiva.

\begin{abstract}
Education in Brazil was only introduced as an important issue according to the need of the moment and inclusive education was no different, its development began to be questioned from movements unsatisfied with the situation. The objective of this research was to investigate the attitudes of physical education teachers in the presence of students with disabilities in their regular classes, for that purpose a questionnaire containing 18 questions was applied. To see if there were differences between the ratios obtained for each statement, we used the chi-square test and the significance level was set at $\mathrm{p}<0.05$. The differences were significant in 15 questions. The participants were 77 teachers in the regular school system of Santo André. Among the participants it was observed that most of them believe in the potential of these students and that inclusion is beneficial to all of those who are part of the school routine. Even with this awareness only $2.6 \%$ reported that they had knowledge to work with students with disabilities and $3.9 \%$ feel prepared to work with this group,
\end{abstract}

${ }^{1}$ Centro Universitário Claretiano - São Paulo, São Paulo - Brasil

${ }^{2}$ Universidade Federal de São Paulo - UNIFESP, São Paulo, São Paulo - Brasil

Contato: educacao.ramos@bol.com.br

Submetido em: 17 maio $2016 \quad$ Aceito em: 25 jun. 2016

\begin{tabular}{|l|l|l|l|l|l|l}
\hline CC Conexões & Campinas, SP & v. 14 & n. 2 & p. 1-16 & abr./jun. 2016 & ISSN 1983-9030
\end{tabular}


however $74 \%$ of teachers reported that they plan to attend courses and lectures related to people with disabilities.

KEYWORDS: Inclusive education. People with disabilities. Inclusive physical education.

\section{RESUMEN}

La educación en Brasil sólo se introdujo como un tema importante de acuerdo con la necesidad de la hora y la educación inclusiva no fue diferente, su desarrollo comenzó a ser cuestionado por los movimientos descontentos con la situación. El objetivo de esta investigación fue determinar las actitudes de los profesores de educación física de la presencia de estudiantes con discapacidad en sus clases regulares para ambos fue un cuestionario con 18 preguntas. Para ver si había diferencias entre los coeficientes obtenidos para cada declaración, se utilizó la prueba de chi-cuadrado y el nivel de significación se fijó en $\mathrm{p}<0,05$. No se detectaron diferencias en 15 preguntas. Los participantes fueron 77 profesores del sistema escolar ordinario del Ayuntamiento de Santo André. Entre los participantes se observó que la mayoría de ellos creen en el potencial de estos estudiantes y que la inclusión es beneficioso para todos los que son parte de la rutina de la escuela. Incluso con esta conciencia sólo el 2,6\% informaron de que tenían conocimiento para trabajar con los estudiantes con discapacidad y el $3,9 \%$ se sienten preparados para trabajar con este grupo, sin embargo el $74 \%$ de los maestros informaron que planean asistir a cursos y conferencias relacionados con la persona con discapacidad.

PALABRAS CLAVE: Educación inclusiva. Personas con discapacidad. Educación física inclusiva. 


\section{INTRODUÇÃO}

A educação no Brasil somente foi discutida como prioridade, quando diferentes necessidades de mão de obra especializada e insatisfação social foram apontadas pela sociedade. ${ }^{1}$ Com as pessoas com deficiência não foi diferente, a educação especial começou a tomar formas e ser questionada no século XVIII por parte dos movimentos liberais, tal qual foi a Inconfidência Mineira e a Conjuração Baiana. ${ }^{1}$

Com a escola criaram-se internamente os conceitos de "normal x anormal", distinguindo as crianças que podiam frequentá-la em detrimento daquelas que não poderiam, portanto ficariam de fora. ${ }^{2}$ Os alunos que não eram classificados ou vistos como "normais" eram excluídos da escola comum e encaminhados para a educação especial, sendo assim a educação especial surge para atender uma parcela de excluídos: os deficientes. ${ }^{3}$

A integração de pessoas com deficiência se fortaleceu em nosso país a partir da promulgação da Constituição Federativa do Brasil em 1988. ${ }^{4}$ Este fortalecimento veio por meio do restabelecimento e da garantia de direitos a educação, conforme disposto no artigo 205 "a educação como direito de todos e dever do Estado e da família" e, artigo 206 que dispõe sobre "igualdade de acesso e permanência na escola," o que proporcionou o surgimento de uma luta a favor da universalização do ensino.

Podemos afirmar que as determinações da Declaração de Salamanca ${ }^{5}$ ao proclamar que os Estados devem assegurar que a educação de pessoas com deficiências seja parte integrante do sistema educacional, foram fundamentais para as discussões e decisões do Brasil, no que se refere à educação especial. A Lei de Diretrizes e Bases da Educação (LDB), ${ }^{6}$ é o documento oficial que veio detalhar as orientações do texto da Constituição Federal e, a partir deste momento as crianças com deficiência passaram a ser incluídas nas escolas regulares, frequentando as mesmas turmas que as demais.

Originalmente a participação de pessoas com deficiência em atividades físicas ocorreu através de programas de ginástica médica, na China, cerca de três mil anos a.C. ${ }^{7}$ No Brasil o desenvolvimento do esporte para pessoas com deficiência física data de 1958 com a fundação do Clube dos Paraplégicos em São Paulo e do Clube do Otimismo no Rio de Janeiro. ${ }^{8}$ 
A prática da educação física é um direito de todos, os programas devem priorizar os grupos menos favorecidos. ${ }^{9}$ A educação física adaptada deve preparar e ensinar os alunos a vibrar com suas conquistas, estimulá-los a buscar novos objetivos e horizontes oferecendo oportunidades para que possam desfrutar das alegrias proporcionadas por esta atividade. ${ }^{10}$

O currículo das Faculdades que preparam futuros professores de educação física para o mercado de trabalho é muito importante para o processo de inclusão, portanto é necessário um olhar crítico sobre o mesmo e até mesmo se necessário reformulá-lo. ${ }^{11}$ A formação profissional desejada deve preparar os futuros professores para atender os alunos com deficiência nos diversos contextos, desde o mais simples até os mais complexos e dinâmicos como, por exemplo, em uma quadra no horário da educação física. ${ }^{12}$ Outro aspecto importante esta relacionado as pesquisas em educação física adaptada que deveriam ter objetivos mais aplicados, a fim de promoverem investigações sobre o campo de atuação profissional. $^{12}$

Professores que até então vislumbravam crianças com deficiência a uma realidade distante, a partir deste momento e aproximação, sentem necessidade de atualização de conhecimentos, através de cursos específicos para recebê-las. Neste contexto, profundas modificações foram aplicadas ao ensino regular e, vem motivando muitas pesquisas na área, especialmente na educação física escolar, porque na maioria das vezes mesmo o aluno com deficiência tendo acesso à escola ele é dispensado das aulas de educação física.

O objetivo desta pesquisa é verificar quais são as atitudes dos professores de educação física da Rede Municipal de Educação de Santo André com a presença de alunos com deficiência em suas aulas regulares.

\section{METODOLOGIA}

O presente estudo trata-se de uma pesquisa descritiva, com recorte transversal, na qual foram levantadas características dos sujeitos envolvidos sem a interferência do pesquisador.

O estudo foi aprovado pelo Comitê de Ética do Centro Universitário Claretiano, parecer n. 845.062, que demonstrava o processo e etapas para a sua aplicação e execução. O Termo de Consentimento Livre e Esclarecido foi assinado por todos os participantes. Finalmente,

\begin{tabular}{l|l|l|l|l|l|l}
\hline (ㄷ) Conexões & Campinas, SP & v. 14 & n. 2 & p. 1-16 & abr./jun. 2016 & ISSN 1983-9030
\end{tabular}


orientamos que a qualquer momento o participante que sentisse constrangido, independente do motivo, poderia desistir da pesquisa, não havendo ônus por esta decisão, bem como não haveria nenhum bônus ao concluí-la.

\section{Caracterização da amostra}

A amostra constituiu-se de 77 professores, sendo 42 do sexo masculino e 35 do sexo feminino em diferentes faixas de idade que lecionavam na Rede Municipal de Educação de Santo André.

A Tabela 1 apresenta o número de participantes da pesquisa distribuídos por sexo faixa etária.

Tabela 1- Composição da amostra por sexo x idade

\begin{tabular}{cccc}
\hline $\begin{array}{c}\text { Faixa } \\
\text { Etária }\end{array}$ & $\begin{array}{c}\text { Sexo } \\
\text { Masculino }\end{array}$ & $\begin{array}{c}\text { Sexo } \\
\text { Feminino }\end{array}$ & Total \\
\hline $20-30$ & 14 & 11 & 25 \\
$31-40$ & 17 & 15 & 32 \\
$41-50$ & 9 & 6 & 15 \\
$51-60$ & 2 & 3 & 5 \\
\hline Total & 42 & 35 & 77 \\
\hline
\end{tabular}

A Tabela 2 apresenta dados sobre a resposta dos professores quanto terem ou não estudado na infância ou adolescência com pessoas com deficiência.

Tabela 2 - Estudou com pessoas com deficiência

\begin{tabular}{llll}
\hline & Homem & Mulher & Total \\
\hline Sim & 12 & 5 & 17 \\
Não & 30 & 30 & 60 \\
\hline
\end{tabular}

Na Tabela 3 visualizamos os dados levantados sobre o curso de graduação e a disciplina de educação física adaptada.

Tabela 3 - Disciplina de Educação Física Adaptada na graduação

\begin{tabular}{cccc}
\hline & Homem & Mulher & Total \\
\hline Sim & 38 & 31 & 69 \\
Não & 4 & 4 & 8 \\
\hline
\end{tabular}


A Tabela 4 demonstra os anos de experiência na área da educação física escolar.

Tabela IV - Experiência com Educação Física Escolar

\begin{tabular}{cccc}
\hline & Homem & Mulher & Total \\
\hline - de 2 anos & 19 & 15 & 34 \\
De 2 a 10 anos & 13 & 12 & 25 \\
+ de 10 anos & 10 & 8 & 18 \\
\hline
\end{tabular}

A Tabela 5 apresenta os dados em relação à participação em cursos na área de educação física adaptada.

Tabela 5 - Participação em Cursos na área de Educação Física Adaptada

\begin{tabular}{cccc}
\hline & Homem & Mulher & Total \\
\hline Sim & 14 & 15 & 29 \\
Não & 28 & 20 & 48 \\
\hline
\end{tabular}

\section{Procedimentos}

Para verificar a atitude dos professores de educação física quanto à presença de alunos com deficiência em suas aulas regulares, foi aplicado o questionário elaborado por Gorgatti e De Rose Júnior ${ }^{13}$ adaptado do modelo de Sideridis e Chandler; ${ }^{14}$ Kozub e Porretta ${ }^{15}$ já validados. Algumas questões foram reformuladas e outras subtraídas do questionário original para que, se adequasse aos objetivos desta pesquisa. As alterações foram necessárias para que pudéssemos realizar a coleta de dados a mais fidedigna possível sobre as atitudes dos professores de educação física diante de alunos com deficiências em suas aulas regulares.

O questionário foi composto de 18 questões, sendo 2 dissertativas e, 16 de múltipla escolha com 5 níveis de respostas:

\begin{tabular}{ll}
\hline Nível & Respostas \\
\hline 0 & Não se aplica \\
1 & Discordo totalmente da afirmação \\
2 & Discordo quase totalmente da afirmação \\
3 & Concordo quase totalmente com a afirmação \\
4 & Concordo totalmente com a afirmação \\
\hline
\end{tabular}


A identificação dos participantes foi resguardada para que os mesmos se sentissem a vontade para responder as perguntas e as suas respostas fossem as mais reais possíveis.

O questionário foi aplicado no Centro de Formação dos Professores "Clarice Lispector", local que os professores de educação física se reúnem todas as segundas-feiras para participarem de cursos de formação específicas. O grupo é composto por professores que trabalham em horário das $7 \mathrm{~h}$ as $12 \mathrm{~h}$ e, das $13 \mathrm{~h}$ às $18 \mathrm{~h}$.

No Quadro 1, apresentamos o questionário utilizado para avaliar a atitude dos professores de educação física diante de alunos com deficiências nas aulas regulares. O modelo foi adaptado de Gorgatti e De Rose Júnior. ${ }^{13}$ 
Quadro 1 - Questionário utilizado para avaliar as atitudes dos professores de educação física

\begin{tabular}{|c|c|}
\hline \multirow{2}{*}{\multicolumn{2}{|c|}{$\begin{array}{l}\text { Prezado (a) Professor (a) } \\
\text { O presente questionário visa avaliar quais as expectativas e experiências do professor ou } \\
\text { professora de Educação Física em relação ao direito de participação dos alunos com deficiência } \\
\text { nas aulas regulares. Você não precisa se identificar e deve assinalar apenas uma alternativa em } \\
\text { cada afirmação, correspondendo àquela que melhor expressa seu grau de concordância. } \\
\text { Desde já, agradeço sua colaboração. } \\
\text { QUESTÕES }\end{array}$}} \\
\hline & \\
\hline 01 & $\begin{array}{l}\text { Eu sinto que tenho o conhecimento suficiente para atingir as necessidades educacionais de } \\
\text { alunos com deficiência. }\end{array}$ \\
\hline 02 & $\begin{array}{l}\text { Com os conhecimentos que possuo, eu me sinto preparado para trabalhar com alunos com } \\
\text { deficiência. }\end{array}$ \\
\hline 03 & Eu sinto que tenho afinidade para trabalhar com alunos com deficiência. \\
\hline 04 & Eu acredito na potencialidade de aprendizagem dos alunos com deficiência. \\
\hline 05 & Eu gosto ou gostaria de ter alunos com deficiência em minhas aulas. \\
\hline 06 & $\begin{array}{l}\text { Eu pretendo participar de cursos e palestras para aumentar meus conhecimentos sobre os } \\
\text { métodos de ensino para alunos com deficiência. }\end{array}$ \\
\hline 07 & $\begin{array}{l}\text { Eu sinto que sou capaz de planejar minhas aulas considerando o direito de participação dos } \\
\text { alunos com deficiência. }\end{array}$ \\
\hline 08 & $\begin{array}{l}\text { Eu sinto que consigo motivar o aluno com deficiência para participar das aulas de Educação } \\
\text { Física. }\end{array}$ \\
\hline 09 & Eu sinto que a atenção oferecida ao aluno com deficiência, em minha aula, é diferenciada. \\
\hline 10 & $\begin{array}{l}\text { Ao planejar minhas aulas procuro abordar, em alguns momentos, a vivência de todos os alunos } \\
\text { em relação às deficiências. }\end{array}$ \\
\hline 11 & $\begin{array}{l}\text { Eu sinto que os alunos sem deficiência irão se beneficiar com a inclusão de colegas com } \\
\text { deficiência nas aulas de Educação Física. }\end{array}$ \\
\hline 12 & $\begin{array}{l}\text { Eu sinto que os alunos com deficiência são aceitos socialmente por seus colegas sem } \\
\text { deficiência. }\end{array}$ \\
\hline 13 & $\begin{array}{l}\text { Eu sinto que os alunos com deficiência são ignorados por seus colegas sem deficiência nas aulas } \\
\text { de Educação Física. }\end{array}$ \\
\hline 14 & $\begin{array}{l}\text { Existem materiais adaptados, na minha escola, suficientes para que eu ensine os alunos com } \\
\text { deficiência. }\end{array}$ \\
\hline 15 & $\begin{array}{l}\text { Eu sinto que tenho informações suficientes da escola a respeito das deficiências apresentadas } \\
\text { pelos alunos. }\end{array}$ \\
\hline 16 & As instalações da escola em que trabalho são adequadas para receber alunos com deficiência. \\
\hline $17 *$ & $\begin{array}{l}\text { Que aspectos você apontaria como imprescindíveis para viabilizar na dinâmica escolar a } \\
\text { proposta da Educação Inclusiva? }\end{array}$ \\
\hline $18^{*}$ & $\begin{array}{l}\text { Quais os aspectos que você apontaria como mais precários, no atual momento, no processo de } \\
\text { inclusão escolar de alunos com deficiência? }\end{array}$ \\
\hline
\end{tabular}

Legenda: *Questões 17 e 18 - dissertativas

Obs: As respostas, das questões de múltiplas escolhas, foram assinaladas de 0 a 4 , representando respectivamente os 5 níveis: 0 - Não se aplica; 1 - Discordo totalmente da afirmação; 2 - Discordo quase totalmente da afirmação; 3 Concordo quase totalmente com a afirmação e 4 - Concordo totalmente com a afirmação.

\section{Análise estatística}

Para as questões de múltipla escolha, foi realizada a análise descritiva da amostra com os resultados apresentado em média, e distribuição percentílica. Para verificar se existiam diferenças entre os resultados em cada resposta das questões de múltipla escolha do questionário, foi aplicado o teste Qui-Quadrado e o nível de significância adotado foi p<0,05. 
Em relação às questões dissertativas para a sua tabulação foi realizado o agrupamento das respostas que eram iguais e apresentada à frequência relativa (\%) da sua ocorrência.

\section{RESULTADOS E DISCUSSÃO}

A Tabela 6 apresenta a distribuição das respostas dos participantes em relação às perguntas do questionário.

Tabela 6 - Distribuição das respostas dos professores e professoras de educação física

\begin{tabular}{|c|c|c|c|c|c|c|}
\hline \multirow{2}{*}{ Questões } & \multicolumn{5}{|c|}{ Respostas } & \multirow{2}{*}{ Teste $x^{2} P$} \\
\hline & $\mathbf{0}$ & 1 & 2 & 3 & 4 & \\
\hline 1 & 6 & 10 & 40 & 19 & 2 & \\
\hline$\%$ & $7.8 \%$ & $13,0 \%$ & $51.9 \%$ & $24.7 \%$ & $2.6 \%$ & $0,000 *$ \\
\hline 2 & 4 & 8 & 39 & 23 & 3 & \\
\hline$\%$ & $5.2 \%$ & $10.4 \%$ & $50.6 \%$ & $29.9 \%$ & $3.9 \%$ & $0,000 *$ \\
\hline 3 & 1 & 4 & 26 & 37 & 9 & \\
\hline$\%$ & $1.3 \%$ & $5.2 \%$ & $33.8 \%$ & $48,0 \%$ & $11.7 \%$ & $0,000 *$ \\
\hline 4 & - & 1 & 6 & 29 & 41 & \\
\hline$\%$ & - & $1.3 \%$ & $7.8 \%$ & $37.7 \%$ & $53.2 \%$ & $0,000 *$ \\
\hline 5 & 8 & 12 & 13 & 35 & 9 & \\
\hline$\%$ & $10.4 \%$ & $15.6 \%$ & $16.9 \%$ & $45.4 \%$ & $11.7 \%$ & $0,000^{*}$ \\
\hline 6 & - & 4 & 3 & 13 & 57 & \\
\hline$\%$ & - & $5.2 \%$ & $3.9 \%$ & $16.9 \%$ & $74,0 \%$ & $0,000^{*}$ \\
\hline 7 & - & 3 & 15 & 40 & 19 & \\
\hline$\%$ & - & $3.9 \%$ & $19.5 \%$ & $51.9 \%$ & $24.7 \%$ & $0,000 *$ \\
\hline 8 & 2 & 1 & 12 & 44 & 18 & \\
\hline$\%$ & $2.6 \%$ & $1.3 \%$ & $15.6 \%$ & $57.1 \%$ & $23.4 \%$ & $0,000 *$ \\
\hline 9 & 1 & 2 & 17 & 45 & 12 & \\
\hline$\%$ & $1.3 \%$ & $2.6 \%$ & $21.1 \%$ & $58.4 \%$ & $15.6 \%$ & $0,000 *$ \\
\hline 10 & 2 & 3 & 16 & 37 & 19 & \\
\hline$\%$ & $2.6 \%$ & $3.9 \%$ & $20.8 \%$ & $48,0 \%$ & $24.7 \%$ & $0,000 *$ \\
\hline 11 & 1 & 2 & 4 & 29 & 41 & \\
\hline$\%$ & $1.3 \%$ & $2.6 \%$ & $5.2 \%$ & $37.7 \%$ & $53.2 \%$ & $0,000 *$ \\
\hline 12 & 1 & 2 & 12 & 39 & 23 & \\
\hline$\%$ & $1.3 \%$ & $2.6 \%$ & $15.6 \%$ & $50.6 \%$ & $29.9 \%$ & $0,000 *$ \\
\hline 13 & 11 & 22 & 22 & 20 & 2 & \\
\hline$\%$ & $14.3 \%$ & $28.6 \%$ & $28.6 \%$ & $25.9 \%$ & $2.6 \%$ & $0,000 *$ \\
\hline 14 & 12 & 33 & 21 & 10 & 1 & \\
\hline$\%$ & $15.6 \%$ & $42.8 \%$ & $27.3 \%$ & $13,0 \%$ & $1.3 \%$ & $0,000^{*}$ \\
\hline 15 & 5 & 19 & 27 & 20 & 6 & \\
\hline$\%$ & $6.5 \%$ & $24.7 \%$ & $35.1 \%$ & $25.9 \%$ & $7.8 \%$ & $0,000^{*}$ \\
\hline 16 & 7 & 14 & 24 & 21 & 11 & \\
\hline$\%$ & $9.1 \%$ & $18.2 \%$ & $31.2 \%$ & $27.2 \%$ & $14.3 \%$ & 0,01227 \\
\hline \multirow{5}{*}{$17 * *$} & \multicolumn{5}{|c|}{$\begin{array}{l}\text { - Formação contínua em relação às diversas deficiências e transtornos para os professores de Educação } \\
\text { Física e também demais funcionários da escola. (teoria e prática). }\end{array}$} & $33 \%$ \\
\hline & \multicolumn{5}{|c|}{ - Participação ativa da Direção da Unidade escolar, da família e comunidade. } & $30 \%$ \\
\hline & \multicolumn{5}{|c|}{ - Discussões periódicas a respeito das inclusões da escola. } & $15 \%$ \\
\hline & \multicolumn{5}{|c|}{ - Entender o que é inclusão. } & $22 \%$ \\
\hline & \multirow{2}{*}{\multicolumn{5}{|c|}{ - Falta de formação específica na área de Educação Física Adaptada (pós-graduação). }} & $100 \%$ \\
\hline \multirow{5}{*}{$18^{* * *}$} & & & & & & $22 \%$ \\
\hline & \multicolumn{5}{|c|}{ - A demanda escolar ocupa todo o tempo, não sendo possível realizar discussões pontuais. } & $33 \%$ \\
\hline & \multicolumn{5}{|c|}{ - Falta de apoio familiar. } & $27 \%$ \\
\hline & \multicolumn{5}{|c|}{ - Acelerar, na área da saúde, os encaminhamentos. } & $18 \%$ \\
\hline & & & & & Total & $100 \%$ \\
\hline
\end{tabular}

Legenda: **Nas questões de números 17 e 18, por serem dissertativas as respostas foram agrupadas para promover sua tabulação. 
A análise estatística demonstrou que houve diferenças significativas $(p<0,05)$ em 15 das 16 questões de múltipla escolha. Somente a questão de número 16 apresentou algum nível de homogeneidade ( $\mathrm{p}=0,012$ ), no qual 14,3\% (11) dos professores pesquisados informaram que as instalações das escolas em que trabalha são adequadas para atenderem aos alunos com deficiência. Em relação às questões dissertativas, por serem questões abertas, foi realizado o agrupamento das respostas iguais e apresentadas à percentagem da sua frequência relativa.

As questões de número 1 ao número 12 e as questões de número 15 e 16 são todas afirmações positivas em relação às ações frente aos alunos com deficiência, diante disso esperava-se que o maior número dos professores que participaram da pesquisa escolhesse a alternativa de número 4, a qual estabelecia concordância total com tal afirmação. Somente a questão de número 13 é que poderíamos classificá-la como uma afirmação negativa e para tanto se esperava que o maior número dos professores escolhesse a alternativa de número 1, discordando totalmente dessa afirmação.

Quando perguntado aos professores se eles tinham conhecimento suficiente para trabalharem com alunos com deficiência (Questão n. 1), somente 2,6\% (02) relataram que sim, ou seja, concordaram totalmente com a afirmação. Nessa mesma linha somente 3,9\% (03), se sentem preparados para trabalharem com essa população (Questão n. 2).

A formação dos professores de educação física é muito importante para o processo de inclusão, ${ }^{11}$ contudo se faz necessário uma reformulação curricular para que realmente os futuros professores ao concluírem o curso de educação física tenham condições de assumirem uma turma e promoverem efetivamente a inclusão. ${ }^{12}$

Em relação à “afinidade” (Questão n. 3), somente 11,7\% (09) concordaram totalmente com essa afirmação, dizendo que tem afinidade com esses alunos, ou seja, enxergam esses alunos como seus semelhantes. Esse deve ser o olhar do professor em relação ao aluno seja ele com alguma deficiência ou não, pois a prática da educação física é um direito de todos e seus programas devem atender aos grupos menos favorecidos da sociedade. ${ }^{9}$ 
A formação é de fundamental importância para o futuro profissional, pois se forem preparados para atenderem somente grupos homogêneos, não poderemos esperar seu incentivo a cooperação e respeito às diferenças, ${ }^{16}$ no entanto, para promover realmente a inclusão se faz necessário que ao planejar as aulas considere as diferenças e nesse caso leve em conta àquele aluno com deficiência (Questão n. 7), contudo somente 24,7\% (19) dos professores concordaram totalmente com a afirmação, observando as características desses alunos.

Quando perguntado se eles gostavam de terem alunos com deficiência em suas turmas (Questão n. 5) somente 11,7\% (09) concordaram totalmente com a afirmação.

Em relação à motivação (Questão n. 8) mesmo sabendo que a motivação é intrínseca, ou seja, ninguém motiva ninguém, se faz necessário criar situações para que a pessoa se motive e com isso participe das atividades propostas com mais alegria e nesse sentido somente $23,4 \%$ (18) dos participantes concordaram totalmente com a afirmação, criando situações para que o aluno tenha motivação para participar das aulas.

Outra questão relevante diz respeito ao acreditar nas potencialidades desses alunos em relação à aprendizagem e nesse sentido mais da metade dos professores, 53,2\% (41) concordaram totalmente com a afirmação. E ainda 15,6\% (12) dos professores concordaram totalmente que a atenção oferecida aos alunos com deficiência é diferenciada em suas aulas (Questão n. 9).

Para mudar o conceito de normal x anormal, criado internamente pela escola ${ }^{2}$ é necessário que a sociedade em geral tenha informações sobre as deficiências, e esse conhecimento deveria iniciar na escola, onde esse sujeito está predisposto a sofrer mudanças e com isso seria oportuno que os professores vivenciassem com todos os alunos as diferenças e nesse caso as deficiências (Questão n. 10), contudo somente 24,7 \% (19) abordam essas ações em seus planejamentos.

A ausência de formação especializada para os professores trabalharem com alunos com deficiência compromete seriamente a implantação de políticas. ${ }^{17}$ Em relação à participação em cursos e palestra (Questão n. 6) para melhorarem seus conhecimentos, 74\% (57)

\begin{tabular}{|l|l|l|l|l|l|l}
\hline CConexões & Campinas, SP & v. 14 & n. 2 & p. 1-16 & abr./jun. 2016 & ISSN 1983-9030
\end{tabular}


concordaram totalmente com essa afirmação. Nessa linha 90 professores de educação física do sistema regular de ensino da cidade de São Paulo foram avaliados e 86,7\% dos professores demonstraram a intenção de fazer cursos na área de educação física adaptada. ${ }^{13}$

Nessa mesma pesquisa 83,3\% dos professores concordaram que os alunos sem deficiência se beneficiam com o movimento da inclusão. Esse benefício (Questão n. 11) também foi apontado pelos professores desta pesquisa onde 53,2\% (41) concordaram totalmente com a afirmação.

Do ponto de vista da aceitação por parte dos demais alunos (Questão n. 12) 29,9\% (23) dos professores concordaram totalmente com a afirmação, relatando que esses alunos são aceitos pelos seus colegas e essas atitudes também foram observadas em 10 professores de educação física sendo cinco da rede regular e cinco da rede particular de ensino, onde $90 \%$ deles acreditavam na aceitação dos deficientes por seus colegas de aula. ${ }^{18} \mathrm{E}$ nesse sentido quando perguntado se durante as aulas de educação física os alunos sem deficiência ignoravam os alunos com deficiência (Questão n. 13) somente 2,6\% (02) concordaram totalmente com a afirmação.

Considerando que a maioria das escolas foram construídas no século passado elas não foram idealizadas para todos, ${ }^{19}$ não são acessíveis o que interfere significativamente no exercício real da inclusão. As barreiras arquitetônicas juntamente com a falta de materiais adaptados foram apontados como empecilhos para a real inclusão, por $90 \%$ dos professores estudados por Gorgatti. ${ }^{17}$ Os dados levantados por esta pesquisa corroboram com a pesquisa citada, pois somente 14,3\% (11) dos professores relataram que suas escolas são adequadas (Questão n. 16) e quando questionado em relação aos materiais adaptados (Questão n. 14) somente 1,3\% (01) concordou totalmente com a afirmação, ou seja, que na sua escola existia material adaptado suficiente para o ensino do aluno com deficiência.

Quando questionado se recebiam da escola (equipe gestora) informações suficientes em relação aos alunos com deficiência (Questão n. 15) somente 7,8\% (06) concordaram totalmente com a afirmação, sugerindo que recebiam essa informação. 
Por fim, algumas manifestações quanto às questões dissertativas. Na questão de número 17, dentre os pesquisados $33 \%$ solicitaram formação contínua em relação às diversas deficiências e também em relação aos transtornos.

Para 30\% dos pesquisados é importante à participação ativa da equipe gestora da unidade escolar, da família dessa criança com deficiência e também da comunidade, $15 \%$ relataram que consideram importante ter discussões periódicas em relação às crianças com deficiência e ainda $22 \%$ não entendem o que seria a inclusão.

Na questão de número 18, a falta de formação específica na área de educação física adaptada (pós-graduação) foi apontada por $22 \%$ dos pesquisados como um dos problemas para a efetivação da inclusão. Para 33\% a interferência no processo de inclusão esta relacionada à demanda escolar, pois segundo eles essa demanda ocupa todo o tempo não sendo possível à realização de discussões pontuais.

Para 27\% dos professores a falta de apoio familiar da criança com deficiência, interfere na inclusão, bem como, a demora no atendimento dessas crianças pelos profissionais da área da saúde, em especial os médicos foi apontado por $18 \%$ dos professores como uma das barreiras para a efetivação da inclusão.

\section{CONSIDERAÇÕES FINAIS}

A pesquisa atendeu seus objetivos ao esboçar o panorama das atitudes dos professores de educação física quanto à presença de alunos com deficiência em aulas regulares. Foi possível observar a necessidade de: investimento na formação e qualificação deste profissional, de quebra de paradigmas, de evolução e realização de novas pesquisas relacionadas ao tema.

\section{REFERÊNCIAS}

${ }^{1}$ JANNUZZI, Gilberta de Martino. A educação do deficiente no Brasil: dos primórdios ao início do século XXI. Campinas: Autores Associados, 2004.

${ }^{2}$ KUPFER, Maria Cristina M.; PETRI, Renata. Por que ensinar a quem não aprende? Estilos da Clínica: revista sobre a infância com problemas, São Paulo, v. 5, n. 9. p. 109-117, 2000. 
${ }^{3}$ MAZZOTTA, Marcos J. S. Educação especial no Brasil: história e políticas públicas. 4. ed. São Paulo: Cortez, 2003.

${ }^{4}$ BRASIL. Casa Civil. Constituição da República Federativa do Brasil. Brasília: Imprensa Oficial, 1988.

${ }^{5}$ BRASIL. Coordenadoria Nacional para Integração da Pessoa Portadora de Deficiência (CORDE). Declaração de Salamanca e linha de ação sobre necessidades educativas especiais. Brasília, 1994.

${ }^{6}$ BRASIL. Ministério da Educação e Cultura. LDB. Lei de Diretrizes e Bases da Educação. Brasília: Imprensa Oficial, 1996.

${ }^{7}$ GORGATTI, Marcia Greguol; COSTA, Roberto Fernandes. Atividade física adaptada. Barueri: Manole, 2005.

${ }^{8}$ MELLO, Marco Túlio; WINCKLER, Ciro. Esporte paralímpico. São Paulo: Atheneu, 2012.

${ }^{9}$ ROSADAS, Sidney de Carvalho. Educação física e prática pedagógica: portadores de deficiência mental. Vitória: Ed. da UFES, 1994.

${ }^{10}$ GORGATTI, Marcia Greguol. Educação física escolar e inclusão: uma análise a partir do desenvolvimento motor e social de adolescentes com deficiência visual e das atitudes dos professores. 205. 173 f. Tese (Doutorado) - Universidade de São Paulo, São Paulo, 2005.

${ }^{11}$ SATO, Carlos; CARDOSO, Ana Maria; TOLOCKA, Rute Estanislava A inclusão de pessoas com necessidades educativas especiais nas escolas regulares: receio ou coragem? In: VENÂNCIO, Silvana; AUGUSTO, Dulce Inês L. S. (Ed.). Pedagogia do movimento: coletânea de textos. Campinas: Unicamp/FEF/DEM, 2002. CD-ROM. 
${ }^{12}$ MAUERBERG-DECASTRO, Eliane. Realizações e perspectivas na área de atividade física adaptada e contribuições da área de comportamento motor. Revista da Sociedade Brasileira de Atividade Motora Adaptada, v. 7, n. 1, p. 33-40, dez. 2002.

${ }^{13}$ GORGATTI, Marcia Greguol; DE ROSE JÚNIOR, Dante. Percepção dos professores quanto à inclusão de alunos com deficiência em aulas de educação física. Movimento, Porto Alegre, v. 15, n. 2, p.119-140, abr./jun. 2009. Disponível em: <http://www.seer.ufrgs.br/Movimento/article/viewFile/2971/5138>. Acesso em: 10 set. 2013. ${ }^{14}$ SIDERIDIS, G. D.; CHANDLER, J.P. Assessment of teacher attitudes toward inclusion of students with disabilities: a confirmatory factor analysis. Adapted Physical Activity Quarterly, Champaign, v. 14, p. 51-64, 1997.

${ }^{15}$ KOZUB, F. M.; PORRETTA, D. L. Interscholastic coache's attitudes toward integration of adolescents with disabilities. Adapted Physical Activity Quarterly, Champaign, v.15, p. 328-344, 1998.

${ }^{16}$ RODRIGUES, David. Educação física perante a educação inclusiva: reflexões conceituais e metodológicas. Revista da Educação Física/UEM, Maringá, v. 14, n. 1, p. 67-73, 2003. Disponível em:

<http://periodicos.uem.br/ojs/index.php/RevEducFis/article/view/3649/2515>. Acesso em: 10 abr. 2014.

${ }^{17}$ SANT' ANA, Izabella Mendes. Educação inclusiva: concepções de professores e diretores. Psicologia em Estudo, Maringá, v. 10, n. 2, p. 227-234, maio/ago. 2005. Disponível em: <http://www.scielo.br/pdf/pe/v10n2/v10n2a09.pdf〉. Acesso em: 14 abr. 2014.

${ }^{18}$ GORGATTI, Marcia Greguol et al. Atitudes dos professores de educação física do ensino regular com relação a alunos portadores de deficiência. Revista Brasileira de Ciência e Movimento, Brasília, v. 12. n 2, p. 63-68, jun. 2004. Disponível em: $<$ http://portalrevistas.ucb.br/index.php/RBCM/article/viewFile/558/582>. Acesso em: 10 set. 2013. 
${ }^{19}$ ALMEIDA, Dulce Barros de. Do especial ao inclusivo? um estudo da proposta de inclusão escolar da rede estadual de goiás, no município de Goiânia. 2003. 204 f. Tese (Doutorado) Faculdade de Educação, Universidade Estadual de Campinas, Campinas, 2003. 